\title{
PENDIDIKAN KESEHATAN TENTANG ERGONOMI DI HOME INDUSTRY COTTON BUD DESA MEKARBAKTI KECAMATAN PAMULIHAN KABUPATEN SUMEDANG
}

\author{
Iwan Shalahuddin ${ }^{1 *}$, Iwan Suhendar², Umar Sumarna ${ }^{3}$ \\ 1,2,3 Fakultas Keperawatan Universitas Padjadjaran Kampus Garut
}

Email korespondensi: shalahuddin@unpad.ac.id

\begin{abstract}
ABSTRAK
Penerapan keselamatan dan kesehatan kerja sangat penting sebagai upaya pencegahan kecelakaan kerja di lingkungan kerja. kerja merupakan hal yang penting bagi perusahaan, karena dampak kecelakaan dan penyakit kerja tidak hanya merugikan karyawan, tetapi juga perusahaan baik secara langsung maupun tidak langsung. Potensi bahaya akan selalu timbul pada saat seseorang yang melakukan pekerjaan. Potensi bahaya tersebut dapat berasal dari sifat pekerjaan yang dilakukan oleh pekerja, mesin yang digunakan oleh pekerja, lingkungan kerja dari pekerja, proses produksi, dan cara kerja pekerja. Tujuan pengabdian untuk menjelaskan tentang kesehatan dan keselamatan kerja khususnya ergonomi dalam pelaksanaan pekerjaan di home industry. Metode kegiatan promosi kesehatan dilakukan dengan pemberian pendidikan kesehatan melalui virtual menggunakan platform Whatsapp Group Chat dengan metode ceramah, Tanya jawab, diskusi dan demonstrasi. Hasil Rekapitulasi data Pengkajian Kebutuhan Belajar Jumlah audience : 36 orang, Audience terdiri dari para pekerja dari seluruh bagian dalam proses pembuatan Cuttond Buds. Saat sesi pematerian berjalan dengan lancar dan peserta tampak fokus dan menyaimak apa yang sedang dipresentasikan. Setelah materi selesai disampaikan, dilanjut dengan penayangan video tentang pengaturan posisi yang baik dan benar pada saat bekerja yang disertai dengan gerakan peregangan dan selanjutnya sesi tanya jawab yang bertujuan untuk mengetahui sejauh mana perubahan pekerja dari yang sebelumnya dan sesudahnya diberikan penkes. Kesimpulan didapatkan bahwa kebutuhan belajar pekerja di home industy cuttond bud, meliputi kebutuhan belajar perceived needs, unperceived needs, dan misperceived needs. Pada proses pelaksanaan penyuluhan; para pekerja, terlihat antusias saat pemberian materi berlangsung. Kegiatan penyuluhan berjalan kondusif karena peserta menyimak materi yang disampaikan dengan baik.
\end{abstract}

Kata Kunci: Ergonomi, Home Industri, Keselamatan dan Kesehatan Kerja

\begin{abstract}
The application of occupational safety and health is very important as an effort to prevent work accidents in the work environment. Work is important for the company, because the impact of accidents and occupational diseases is not only detrimental to employees, but also to the company, either directly or indirectly. Potential danger will always arise when someone is doing the job. The potential hazards can come from the nature of the work done by workers, the machines
\end{abstract}


used by workers, the work environment of workers, the production process, and the way workers work. The purpose of this service is to explain about occupational health and safety, especially ergonomics in the implementation of work in the home industry. The method of health promotion activities is carried out by providing virtual health education using the Whatsapp Group Chat platform with the methods of lectures, questions and answers, discussions and demonstrations. Results of the Learning Needs Assessment data recapitulation Audience number: 36 people. Audience consists of workers from all parts of the process of making cuttond buds. When the presentation session went smoothly and the participants seemed focused and listening to what was being presented. After the material has been delivered, it is followed up with a video showing about setting a good and correct position at work accompanied by stretching movements and then a question and answer session which aims to find out the extent to which workers have changed from those previously and afterwards given the Health Center. The conclusion is that the learning needs of workers at home industrial cuttond buds include learning needs, perceived needs, unperceived needs, and misperceived needs. In the extension process; the workers, looked enthusiastic when the materials were given. The extension activity was conducive because the participants listened well to the material presented.

Keywords: Ergonomics, Home Industry, Occupational Safety and Health

\section{PENDAHULUAN}

Keselamatan dan kesehatan kerja adalah upaya perlindungan untuk tenaga kerja dan orang lain yang berada di tempat kerja agar dapat terhindar dari potensi yang dapat menimbulkan bahaya, sehingga tenaga kerja tersebut selalu dalam kondisi selamat dan sehat. Keselamatan dan kesehatan kerja juga merupakan ilmu untuk pengendalian bahaya serta risiko untuk dapat meminimalkan terjadinya accident dan injury, serta upaya pencegahan terhadap tenaga kerja yang mengalami gangguan kesehatan yang disebabkan oleh kondisi pekerjaan maupun dari lingkungan kerja dari tenaga kerja tersebut (Suryani, dkk, 2013).

Potensi bahaya akan selalu timbul pada saat seseorang yang melakukan pekerjaan. Potensi bahaya tersebut dapat berasal dari sifat pekerjaan yang dilakukan oleh pekerja, mesin yang digunakan oleh pekerja, lingkungan kerja dari pekerja, proses produksi, dan cara kerja pekerja. Untuk meminimalkan terjadinya potensi bahaya tersebut, adalah dengan menerapkan keselamatan dan kesehatan kerja (Suryani, dkk, 2013).

Penerapan keselamatan dan kesehatan kerja sangat penting sebagai upaya pencegahan kecelakaan kerja di lingkungan kerja. kerja merupakan hal yang penting bagi perusahaan, karena dampak kecelakaan dan penyakit kerja tidak hanya merugikan karyawan, tetapi juga perusahaan baik secara langsung maupun tidak langsung Kesehatan kerja dalam keperawatan atau yang biasa disebut dengan occupational healthnurse memiliki tujuan untuk membuat tenaga kerja selalu sehat, selamat, dapat bekerja secara produktif, sejahtera, memiliki daya saing yang tinggi, sehingga tenaga kerja tidak ada yang sakit ataupun dalam kondisi yang tidak sehat dan menjadikan tenaga kerja tersebut dapat bekerja secara produktif, serta tidak terjadi kecelakaan kerja yang dapat mengganggu kegiatan produksi dalam pekerjaan (Kurniawidjaja, 2010). 
Perawat kesehatan kerja memberikan program dan layanan kesehatan dan keselamatan kepada pekerja. Area praktik khusus ini berfokus pada promosi dan pemulihan kesehatan, 2 pencegahan penyakit dan cedera, perlindungan dari bahaya terkait pekerjaan dan lingkungan, dan profitabilitas perusahaan (American Association of Occupational Health Nurses, 2017).

Keselamatan dan Kesehatan Kerja pada home industry sangat penting untuk dipersiapkan agar terhindarnya dari bahaya atau kecelakaan yang mungkin saja terjadi. Kecelakaan dapat terjadi akibat kelalaian dari perusahaan, pekerja, maupun keduanya, dan akibat yang ditimbulkan dapat memunculkan trauma bagi kedua pihak. Bagi pekerja, cedera akibat kecelakaan dapat berpengaruh terhadap kehidupan pribadi, kehidupan keluarga, dan kualitas hidup pekerja tersebut. Sedangkan bagi perusahaan, kerugian produk dan waktu yang terbuang karena penyelidikan atas kecelakaan tersebut, serta biaya untuk melakukan proses hukum atas keselamatan kerja.

Konsep ergonomi serta keselamatan kesehatan kerja merupakan konsep penting untuk diterapkan dalam suatu industri, khususnya dalam perancangan stasiun kerjanya. Kecenderungan yang ada saat ini adalah, pada industri skala kecil menengah. Konsep tersebut kurang begitu diperhatikan, sehingga dapat menimbulkan resiko kerja baik dari segi bahaya kondisi lingkungan fisik, sikap dan cara kerja (Laksmiwaty, 2009). Tujuan penerapan ergonomi adalah untuk peningkatan kualitas kehidupan yang lebih baik. Dengan penerapan ergonomi ini, maka akan tercipta lingkungan kerja aman, sehat dan nyaman sehingga kerja menjadi lebih produktif dan efisien serta adanya jaminan kualitas kerja (Tim Ergoinstitute, 2008).

Ergonomi adalah suatu cabang ilmu yang memanfaatkan informasiinformasi mengenai sifat, kemampuan dan keterbatasan manusia dalam rangka membuat sistem kerja yang ENASE (efektif, nyaman, aman, sehat dan efisien). Ergonomi dan K3 (Keselamatan dan Kesehatan Kerja) merupakan dua hal yang tidak dapat dipisahkan.Keduanya mengarah kepada tujuan yang sama yakni peningkatan kualitas kehidupan kerja (quality of working life). Aspek kualitas kehidupan kerja merupakan salah satu faktor penting yang mempengaruhi rasa kepercayaan dan rasa kepemilikan pekerja kepada perusahaan, yang berujung kepada produktivitas dan kualitas kerja (Arif, 2009).

\section{MASALAH}

Perkembangan teknologi saat ini begitu pesatnya, sehingga peralatan sudah menjadi kebutuhan pokok pada berbagai lapangan pekerjaan. Artinya peralatan dan teknologi merupakan penunjang yang penting dalam upaya meningkatkan produktivitas untuk berbagai jenis pekerjaan. Disamping itu disisi lain akan terjadi dampak negatifnya, bila kita kurang waspada menghadapi bahaya potensial yang mungkin timbul. Hal ini tidak akan terjadi jika dapat diantisipasi pelbagai risiko yang mempengaruhi kehidupan para pekerja. Pelbagai risiko tersebut adalah kemungkinan terjadinya Penyakit Akibat Kerja, Penyakit yang berhubungan dengan pekerjaan dan Kecelakaan Akibat Kerja yang dapat menyebabkan kecacatan atau kematian. Antisipasi ini harus dilakukan oleh 
semua pihak dengan cara penyesuaian antara pekerja, proses kerja dan lingkungan kerja. Pendekatan ini dikenal sebagai pendekatan ergonomik.

Bekerja dengan tubuh dan lingkungan yang sehat, aman serta nyaman merupaka hal yang diinginkan oleh semua pekerja. Di era globalisasi menunutu pelaksanaan Kesehatan dan Keselamaan Kerja (K3) di setiap tempat kerja termasuk di sector kesehatan. Untuk itu perlu kita mengembangkan dan mingkatkan $\mathrm{K} 3$ di sector kesehatan dalam rangka menekan serendah mingki risiko kecelakaan dan penyakit yang timbul akibat hubungan kerja, serta meningkatkan produktivitas dan efisiensi.

Berbagai permasalahan yang dihadapi pada bidang ergonomi dan $\mathrm{K} 3$ (Kesehatan dan Keselamatan Kerja) dalam sebuah industri adalah sebuah hal yang penting untuk dikaji. Pasalnya, hal tersebut berhubungan dengan keamanan dan kenyamanan dalam bekerja, yang bisa menentukan baik atau buruknya formasi kerja dalam suatu industri. Pendekatan ergonomi sendiri merupakan suatu upaya dalam bentuk ilmu, teknologi, dan seni yang dapat menyelaraskan peralatan, mesin, pekerjaan, sistem, organisasi, dan lingkungan dengan kemampuan dan keterbatasan yang dimiiki oleh manusia. Dengan begitu, diharapkan akan tercapai sebuah kondisi dan lingkungan yang sehat, aman, nyaman, efisien dan produktif, melalui pemanfaatan fungsional tubuh manusia secara lebih optimal dan maksimal.

Pencapaian manajemen Kesehatan dan Keselamatan Kerja (K3) sangat tergantung pada faktor ergonomi yang diperhatikan oleh perusahaan. Meski demikian, kenyataan di lapangan menunjukkan bahwa kecelakaan kerja masih kerap terjadi di berbagai perusahaan yang secara administratif telah lulus atau telah melengkapi audit sistem manajemen K3. Melihat realita tersebut, seharusnya perusahaan bisa belajar dari ungkapan "without ergonomics, safety managements is not enough", tanpa ergonomi manajemen keselamatan tidaklah cukup. Dengan demikian, mereka tidak akan lagi mengesampingkan keluhan para pekerja yang terkait dengan penurunan kemampuan kerja berupa kelainan pada sistem otot-rangka (musculoskeletal disorders) di dalam mekanisme dan sistem audit Kesehatan dan Keselamatan Kerja (K3).

Ergonomi akan tercapai apabila fisik para pekerja berada dalam kondisi yang benar-benar optimal. Setiap pekerja akan mencapai kesehatan fisik yang benar-benar jika tingkat konsumsi gizi, pemberdayaan tenaga yang baik, sikap tubuh yang baik, serta efisiensi waktu benar-benar diperhatikan. Para pekerja harus mengetahui dan memahami berapa banyak takaran energi yang meliputi jumlah, kualitas, frekuensi, selera, kebiasaan, dan kemampuan yang diperlukan oleh tubuh untuk melakukan aktivitas tersebut.

Berdasarkan latar belakang di atas, untuk meminimalisasi terjadinya dan dampaknya, perlu diberikan arahan dan pendidikan ilmu pengetahuan yang berkelanjutan, salah satunya dengan memberikan Pendidikan kesehatan tentang ergonomi pelaksanaan kerja yang sesuai dengan bidangnya masing-masing di home Industry Cuttond Bud Kecamatan Pamulihan Kabupaten Sumedang. 


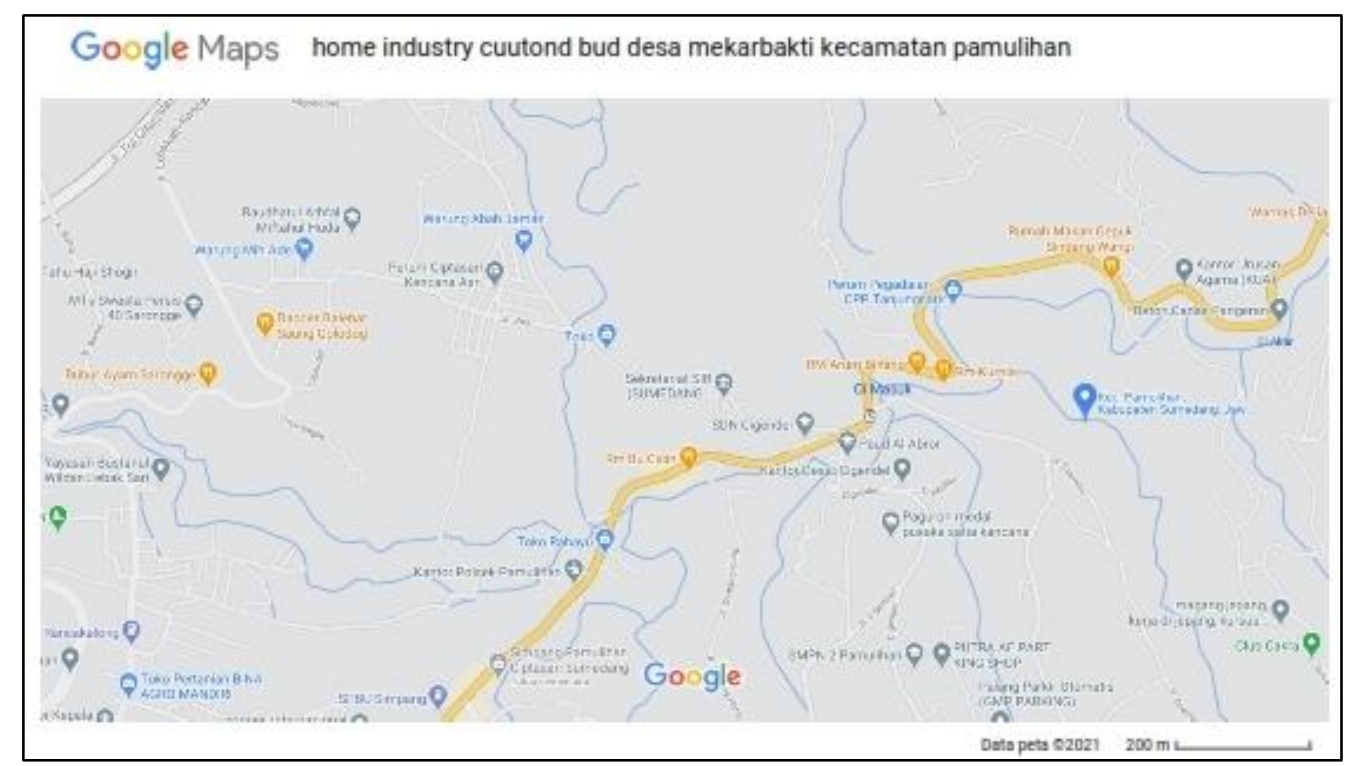

Gambar 1. Peta Lokasi Home Industry Cuttond Bud Pamulihan Sumedang

\section{METODE.}

Metode yang dilakukan dalam pendidikan kesehatan adalah penjelasan atau ceramah yang diberikan oleh pemateri kepada pekerja dan pemilik home industry kerajinan Cotton bud secara virtual, dan diikiuti dengan tanya jawab, pemateri harus memastikan semua pekerja mengerti materi yang telah disampaikan dengan memastikan kembali kepada peserta apabila ada hal-hal yang kurang jelas. Melakukan Pre Test tentang Ergonomi melalui pertanyaan secara lisan dan Melaksanakan penyuluhan kesehatan pentinggnya upaya melakukan ergonomi yang baik dan benar selama melaksanakan pekerjaan agar terhindar dari gangguan kesehatan dan gangguan keselamatan kerja. Media informasi bagi pekerja ini disusun oleh tim pengabdian pada masyarakat yang bekerjasama dengan mahasiswa serta melakukan Post Test melalui pertanyaan secara lisan.

Metode yang digunakan antara lain Ceramah/ Lecture: Metode penyuluhan dengan cara ceramah atau lecture dapat mempermudah peserta untuk memahami isi dari materi yang akan disampaikan sebagai IImu pengetahuan. Metode ceramah atau lecture ini akan diberikan bersamaan dengan power point materi yang akan di bahas; Metode Tanya jawab yang merupakan usaha penyingkiran rintangan selama atau sesudah berlangsungnya masa ceramah. Hal ini untuk mempermudah para peserta menanyakan soal tentang materi yang diberikan. Dengan proses belajar mengajar/ penyampaian materi, bertanya memegang peranan yang penting. Pertanyaan yang baik dengan teknik pengajuan yang tepat; Metode Diskusi agar pekerja mampu memecahkan masalah yang dihadapi dari pertanyaan-pertanyaan yang diberikan berkaitan dengan topik pembahasan materi. Metode diskusi juga bertujuan untuk tukar menukar gagasan, pemikiran, informasi/pengalaman diantara peserta, sehingga dicapai kesepakatan pokok-pokok pikiran (gagasan ,kesimpulan). Kespakatan pikiran inilah yang kemudian ditulis sebgai hasil diskusi; Metode demonstrasi dengan memutarkan video posisi ergonomi yang baik dan benar. Sehingga , setelah video diputar, diharapkan peserta dapat memahami, mengingat, sekaligus mendapatkan gambaran bagaimana cara ergonomi yang baik dan benar 
di saat melakukan pekerjaan. Dengan mendemonstrasikan, maka akam menstimulasi semua panca indera para peserta.

\section{HASIL DAN PEMBAHASAN}

Home industry kerajinan Cotton bud ini adalah usaha Tn. M yang merupakan salah satu industri masyarakat yang ada di Desa Mekarbakti Kecamatan Pamulihan Kabupaten Sumedang. Home industri ini baru didirikan pada tahun 2018, home industri ini memiliki halaman yang luas. Home industri ini memiliki 80 pegawai yang dimana merupakan pegawai tetap, namun melakukan pekerjaanya di rumah masing-masing, untuk jam kerja pembuatan cotton bud ini tidak di tentukan namun pegawai biasanya melakukan pekerjaan sekitar 8 jam dan istirahat bekerja selama 1 jam/hari. Home industri ini bersatu dengan rumah Tn. M sebagai pemilik, bangunannya beratap genteng, lantai semen, dan untuk pencahayaan masuk kedalam ruangan. Ruangan untuk Cotton bud ini terdapat satu ruangan yang terbuka, dari cara pembuatan sampai selesai untuk dipasarkan. Bagian depan merupakan tempat halaman yang luas untuk menjemur cotton bud. Pada home industri ini terdapat toilet untuk pegawai dan juga tidak mempunyai dapur untuk mempersiapkan makanan bagi para pegawai.

Selama bekerja, seluruh pegawai ada yang memakai alat pelindung diri ada yang tidak contohnya memakai masker. Penyediaan alat P3K juga tidak ada, jika ada pekerja yang sakit atau mengalami kecelakaan selama bekerja mereka berobat secara mandiri, dan semua pegawai tidak ada yang memiliki jaminan kesehatan. Dalam kajian kesehatan kerja terdapat beberapa aspek yaitu terdiri dari karakteristik pekerja (Usia Pekerja berkisar antara 21-51Tahun, Kebanyakan pekerja perempuan), kondisi fisik pekerja (Tidak ada pekerja yang memiliki kecacatan fisik, Ada keluhan yang berhubungan dengan punggung dan sendi atau pegal-pegal), ergonomi (Posisi kerja para pekerja lebih banyak duduk dan membungkuk), penggunaan APD (Selama bekerja para pegawai ada yang tidak memakai alat pelindung diri seperti masker), Aspek sistem kesehatan (Tidak terdapat kotak P3K ditempat kerja. Seluruh pegawai tidak memiliki jaminan kesehatan).

Berdasarkan hasil rekapitulasi hasil pengkajian kebutuhan belajar dapat terlihat bahwa ada sebagian peserta, kebutuhan belajar yang termasuk kedalam kebutuhan belajar : Perceived needs Karena ada sebagian mengetahui dampak dari tidak melakukan upaya ergonomi yang baik dan benar; Unperceived needs Karena ada sebagian pekerja yang belum mengetahui dampak dari tidak melakukan posisi kerja yang baik dan benar yang berbahaya bagi kesehatan; Misperceived needs Karena ada sebagian pekerja yang mengetahui jika bahaya dari tidak melakukan upaya ergonomi yang baik dan benar yang berbahaya bagi kesehatan, tetapi masih ada kebiasaan yang tidak sesuai dengan ketentuan ergonomi yang baik. Data Rekapitulasi Hasil Pengkajian Kebutuhan Belajar Jumlah audience : 36 orang, Audience terdiri dari para pekerja dari seluruh bagian dalam proses pembuatan Cuttond Buds.

Kegiatan pendidikan kesehatan yang dilaksanakan pada hari Senin, 05 Oktober jam 09.00 - selesai WIB, dilakukan secara virtual melalui aplikasi whatsapp group. Kegiatan ini dimulai dengan pembukaan oleh MC, lalu sambutan. Kegiatan diawali dengan MC menanyakan sejauh mana peserta mengetahui tentang ergonomi dalam bekerja, apakah peserta pernah mengalami gangguan kesehatan akibat ergonomi terutama posisi dalam bekerja, dan dampak apa saja yang akan muncul apabila tidak melakukan upaya pencegahan tersebut. Dari 
semua jawaban peserta, peserta cukup mengenal dengan bahaya dari tidak melakukan upaya melakukan posisi kerja yang baik dan benar, namun peserta masih belum paham mengenai dampak apa saja yang akan timbul pada pekerja yang mengalami kebiasaan tidak melakukan memperhatikan ergonomi yang baik dan benar. Kemudian peserta diberi pre test secara lisan untuk mengetahui sejauh mana pengetahuan nya sebelum materi disampaikan oleh pemateri.

Kegiatan dilanjutkan dengan pemberian materi menggunakan PPT dan penampilan video yang sudah disiapkan, agar peserta tetap tertarik untuk mengikuti acara dan tidak bosan. Materi yang disampaikan ialah mengenai tentang ergonomi pada K3 terutama Posisi yang Baik dan Benar Saat Bekerja. Pemberian materi diawali dengan materi ini, pemateri langsung menampilkan PPT yang sudah disiapkan. Saat sesi pematerian berjalan dengan lancar dan peserta tampak fokus dan menyaimak apa yang sedang dipresentasikan. Setelah materi selesai disampaikan, dilanjut dengan penayangan video tentang pengaturan posisi yang baik dan benar pada saat bekerja yang disertai dengan gerakan peregangan dan selanjutnya sesi tanya jawab yang bertujuan untuk mengetahui sejauh mana perubahan pekerja dari yang sebelumnya dan sesudahnya diberikan penkes. Pertanyaan dibacakan oleh pemateri dan peserta antusias untuk menjawab pertanyaan, total ada 5 pertanyaan yang dijawab semua dengan benar oleh beberapa orang peserta.

Sebelum dilakukan pendidikan kesehatan, peserta didik yaitu pegawai dan pemilik home industry diberikan terlebih dahulu link pre test dan setelah pendidikan kesehatan diberikan link post test sebagai evaluasi pembelajaran. Sayangnya implementasi ini belum cukup efektif sehingga rencana tindak lanjut yang akan dilakukan yaitu dengan berkoordinasi dengan pemilik home industry untuk memantau keselamatan dan kesehatan pekerja pabrik, memfollow up kepada pemilik atau pegawai dalam keseharian terkait materi yang telah disampaikan, meminta kesediaan pegawai untuk menyebar e-poster pada pegawai yang tidak ikut berpartisipasi dalam pendidikan kesehatan, dan memberikan poster edukasi dalam bentuk fisik ke pemilik home industry untuk dipasang ditempat.

Evaluasi penyuluhan mengenai Posisi yang Baik dan Benar Saat Bekerja dilaksanakan secara virtual dengan jumlah peserta kurang lebih 36 peserta. Peserta penyuluhan terlihat antusias saat pemberian materi berlangsung. Peserta mengikuti penyuluhan dengan senang hati karena penyuluhan dilaksanakan dengan menyenangkan. Kegiatan penyuluhan berjalan kondusif karena peserta memperhatikan materi yang disampaikan dengan baik. Hal ini dibuktikan dengan banyaknya peserta yang tertarik untuk menjawab pertanyaan ketika sesi tanya jawab.

Efektifnya fungsi media ajar yang digunakan dapat terlihat jelas oleh seluruh peserta. Karena penyuluhan dilakukan secara virtual sehingga para peserta tidak perlu harus berbondong bondong hadir ke suatu tempat, teteapi cukup hanya dengan menyimak dari virtual di tempat tinggalnya dan tempat kerjanya masing-masing. Hal ini dapat menjadikan keefektifan penjelasan materi. Respon peserta yang baik terlihat dengan antusias untuk mengikutinya dari awal hingga akhir kegiatan.

Kegiatan ini dilaksanakan melalui penyuluhan online, yaitu dengan kuliah lewat whatsapp (KULWAP) dalam grup. Kuliah ini dilakukan sesuai dengan rencana yang telah disusun. Upaya yang dilakukan merupakan bagian dari upaya pencegahan (preventif) dan pendidikan kesehatan (promotif) dalam upaya mencegah terjadinya gangguan kesehatan dan keselamatan akibat kerja. 
Ditinjau dari proses terjadinya perubahan perilaku dalam teori Health Belief Model, perilaku akan berubah salah satunya yaitu jika individu diberikan pemahaman tentang keuntungannya. Dicari dulu penyebab dari suatu perilaku yang kurang baik, lalu diberikan penyuluhan serta informasi yang terinci tentang keuntungan dari perbaikan perilakunya. Upaya ini dilakukan dalam pendidikan kesehatan di home industry cuttond buds di Kabupaten Sumedang.

Menurut teori transtheoritical model perubahan perilaku dimaknai sebagai proses perkembangan yang berlangsung dalam rentang waktu tertentu dan melalui beberapa tahap. Dalam proses pendidikan kesehatan ini, pengajar dapat mengetahui pesertanya berada pada tahap apa. Selama proses pendidikan kesehatan melalui edukasi diketahui bahwa mayoritas peserta berada pada tahap contemplation yaitu individu berada dalam tahap lebih peduli terhadap sisi positif dan negatif dari perubahan perilaku yang direncanakan, namun masih merasa bimbang untuk benar-benar akan melakukannya, sehingga hal ini dapat menjadikan individu menunda perubahan.

Theory of Reasoned Action paling berhasil ketika diaplikasikan pada perilaku yang di bawah kendali individu yang bersangkutan. Jika perilaku tersebut tidak sepenuhnya di bawah kendali atau kemauan individu, ia mungkin tidak akan secara nyata menampilkan perilaku tersebut, dalam hal ini yaitu merubah kebiasaan tidak mencuci tangan. Selama proses pendidikan kesehatan, pengajar berusaha agar individu mempunyai motivasi dan secara mandiri dapat berubah.
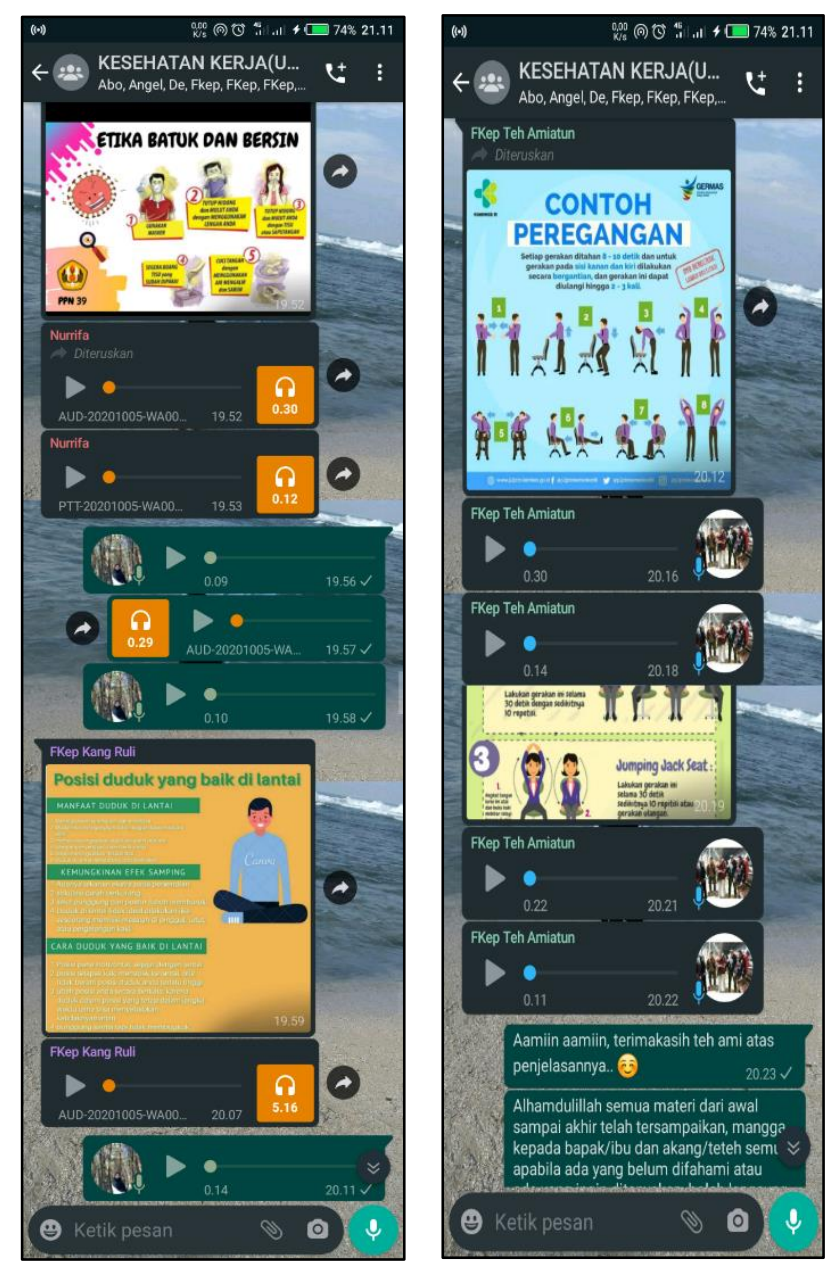

Gambar.1. Poto Kegiatan Edukasi Virtual 


\section{KESIMPULAN}

Dari hasil pengkajian kebutuhan belajar didapatkan bahwa kebutuhan belajar pekerja di home industy cuttond bud, meliputi kebutuhan belajar perceived needs, unperceived needs, dan misperceived needs. Pada proses pelaksanaan penyuluhan; para pekerja, terlihat antusias saat pemberian materi berlangsung. Kegiatan penyuluhan berjalan kondusif karena peserta menyimak materi yang disampaikan dengan baik.

Rencana berkelanjutan program dimasa yang akan datang adalah: Memberikan pemahaman tentang pentingnya melakukan upaya upaya pencegahan terhadap gangguan kesehatan dan keselamatan kerja dengan memperhatikan ergonomis pada saat bekerja; Kegiatan interaktif melalui media sosial secara dua arah mengenai masalah yang dihadapi secara intensif kepada pekerja agar terbangun kebiasaan hidup bersih dan sehat yang kuat dalam melaksanakan pekerjaanya; Melibatkan stakeholder setempat dan pemilik home industri dalam upaya pencegahan perilaku kebiasaan tidak sehat baik dilingkungan rumah maupun lingkungan kerja; Mengusulkan home industry cuttond bud sebagai bentuk home industry percontohan dalam pelaksanaan ergonomi kesehatan dan keselamatan kerja (K3) di kabupaten Sumedang.

\section{DAFTAR PUSTAKA}

Arif, C. (2009). Aspek Ergonomik di Bidang Kedokteran Gigi. Universitas Padjajaran. Bandung.

Bahasa, K. B. B. I. P., \& Keempat, E. (2011). Jakarta: Departemen Pendidikan Nasional. Gramedia Pustaka Utama.

CAHYATI, N. (2014). Peranan Kesehatan dan Keselamatan Kerja (K3) dalam Memperlancar Aktivitas Kerja Karyawan pada PT Sinar Sosro Pabrik Palembang (Doctoral dissertation, Politeknik Negeri Sriwijaya).

Djamaludin, D., Tyas, Y., \& Trismiyana, E. (2019). Hubungan Lingkungan Kerja Dengan Kejadian Musculoskeletal Disoders Pada Perawat Di Rsud Zainal Abidin Pagaralam Way Kanan. Holistik Jurnal Kesehatan, 13(2), 154-162..

Ergoinstitute, T. (2008). Kisah Sukses Penerapan Ergonomi. Bandung: Ergo News. Edisi, 3.

Evadarianto, N., \& Dwiyanti, E. (2017). Postur Kerja Dengan Keluhan Musculoskeletal Disorders Pada Pekerja Manual Handling Bagian Rolling Mill. The Indonesian Journal of Occupational Safety and Health, 6(1), 97-106.

Fernalia, F., Listiana, D., \& Monica, H. (2021). Pengaruh Senam Ergonomik Terhadap Tekanan Darah Pada Pasien Dengan Hipertensi Di Wilayah Kerja Puskesmas Bentiring Kota Bengkulu. Malahayati Nursing Journal, 3(1), 1-10.

Jati Kusuma, I., \& Darmastuti, I. (2011). Pelaksanaan program keselamatan dan kesehatan kerja karyawan PT. Bitratex Industries Semarang (Doctoral dissertation, Universitas Diponegoro).

Karim, Y. Z. (2011). Gambaran Keluhan Muskuloskeletal di PT. Industri Kapal Indonesia (Persero) Makassar Tahun 2011 (Doctoral dissertation, Universitas Islam Negeri Alauddin Makassar).

Kurniawidjaja, L. M. (2010). Teori dan aplikasi kesehatan kerja. Penerbit Universitas Indonesia. 
Salikunna, N. A., \& Towidjojo, V. D. (2011). Penerapan Sistem Manajemen Kesehatan dan Keselamatan Kerja di Rumah Sakit Bersalin Pertiwi Makassar. Biocelebes, 5(1).

Sedarmayanti, H. J. (2018). Tata Kerja dan Produktivitas Kerja.

Somad, I. (2013). Teknik efektif dalam membudayakan keselamatan dan kesehatan kerja. Jakarta: Dian Rakyat..

Suryani, A. I., Isranuri, I., \& Wahyuni, E. L. (2013). Pengaruh Potensi Bahaya terhadap Risiko Kecelakaan Kerja di Unit Produksi Industri Migas PT. X Aceh. Precure, 1, 160116.

Tresnaningsih, E. (2010). Kesehatan dan keselamatan kerja laboratorium kesehatan. Pusat Kesehatan Kerja Setjen Depkes RI. 